\title{
Prevalences and associated factors of electrocardiographic abnormalities in Chinese adults: a cross-sectional study
}

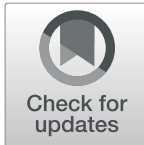

Liping $\mathrm{Yu}^{1 \dagger}$, Xiaojun $\mathrm{Ye}^{2 \dagger}$, Zhaojun Yang ${ }^{1}$, Wenying Yang ${ }^{1}$, Bo Zhang ${ }^{1 *}$ (D) and on behalf of the China National Diabetes and Metabolic Disorders Study Group

\begin{abstract}
Background: Electrocardiogram (ECG) is widely used to screen cardiac diseases. To date, no large population study has provided estimates of the prevalences of ECG findings in China. We aim to investigate the prevalences and associated factors of ECG abnormalities in a general population of Chinese adults.

Methods: ECG data were obtained from 34,965 participants in the 2007-2008 China National Diabetes and Metabolic Disorders Study. ECG abnormalities were classified according to the Minnesota coding (MC) criteria. Prevalences of variant ECG abnormalities were calculated. The associations between ECG abnormalities and gender, age and other risk factors for cardiovascular diseases (CVD) were analyzed by multivariate logistic regression test.

Results: The prevalences of major arrhythmias were 1.70, 2.37 and 1.04\% in the whole population, men and women, respectively. Atrial fibrillation/flutter was found in $0.35 \%$ of men and $0.20 \%$ of women. ST depression and T abnormalities accounted for $10.96,7.54$ and $14.32 \%$ in the whole population, men and women, respectively. Independent of gender and other CVD risk factors, older age significantly increased the odds of having atrial fibrillation/flutter, complete left bundle branch block, complete right bundle branch block, sinus tachycardia, atrial/junctional/ventricular premature beats, ST depression and T abnormalities, tall $\mathrm{R}$ wave left, left/right atrial hypertrophy, left axis deviation and low voltage. Hypertension, overweight, obesity and hypercholesterolemia all independently increased the odds of having ST depression and T abnormalities. History of cardiovascular/cerebrovascular diseases was positively associated with major arrhythmias, ST depression and T abnormalities and tall R wave left.
\end{abstract}

Conclusions: This study provides estimates of the prevalences of ECG findings in a large population of Chinese adults. Gender, age, CVD risk factors and history of cardiovascular/cerebrovascular diseases were significantly associated with ECG abnormalities.

Keywords: Prevalence, Electrocardiogram abnormalities, Arrhythmia, CVD risk factors

\footnotetext{
* Correspondence: drbozhang@yahoo.com

${ }^{\dagger}$ Liping Yu and Xiaojun Ye contributed equally to this work.

${ }^{1}$ Department of Endocrinology, China-Japan Friendship Hospital, Beijing,

China

Full list of author information is available at the end of the article
}

(c) The Author(s). 2020 Open Access This article is licensed under a Creative Commons Attribution 4.0 International License, which permits use, sharing, adaptation, distribution and reproduction in any medium or format, as long as you give appropriate credit to the original author(s) and the source, provide a link to the Creative Commons licence, and indicate if changes were made. The images or other third party material in this article are included in the article's Creative Commons licence, unless indicated otherwise in a credit line to the material. If material is not included in the article's Creative Commons licence and your intended use is not permitted by statutory regulation or exceeds the permitted use, you will need to obtain permission directly from the copyright holder. To view a copy of this licence, visit http://creativecommons.org/licenses/by/4.0/. The Creative Commons Public Domain Dedication waiver (http://creativecommons.org/publicdomain/zero/1.0/) applies to the data made available in this article, unless otherwise stated in a credit line to the data. 


\section{Background}

The electrocardiogram (ECG) is an inexpensive and convenient tool that has been widely used to screen arrhythmias and cardiovascular diseases (CVDs). The prevalences of variant ECG abnormalities and their association with age and CVD risk factors have been reported in several large population studies conducted in North American, South American and European countries [1-3]. The prevalence of major ECG abnormalities has been reported to vary from 6.0 to $11.3 \%$ in men and from 4.3 to $12.9 \%$ in women in previous studies, with differences dependent on various racial backgrounds and targeted age groups [1-4]. Older age has been positively associated with the prevalences of major ECG abnormalities and several specific ECG findings [2, 3, 5]. A previous cross-sectional survey reported that arrhythmias accounted for $4.8 \%$ in men and $3.6 \%$ in women from 65 to 74 years old, while the prevalences of arrhythmias were less than $0.5 \%$ in both men and women under 45 years old [1]. Other CVD risk factors, such as hypertension and diabetes, increased the odds of having major ECG abnormalities and some specific ECG findings $[1,2]$.

To date, no large population study has provided estimates of the prevalences of ECG findings in different age groups in China. Most previous ECG studies performed in China were regional or focused on specific types of ECG findings [6, 7]. The ECG data presented in this study were obtained from 34,965 participants in the China National Diabetes and Metabolic Disorders Study from June 2007 to May 2008. The objective of the present study was to investigate the prevalences of ECG findings in the general population of Chinese adults and determine the associations between ECG abnormalities and age, gender and other CVD risk factors.

\section{Methods}

\section{Participants studied}

The China National Diabetes and Metabolic Disorders Study was a population-based cross-sectional study carried out from June 2007 to May 2008 [8]. The details of its sampling methods have been described previously $[8,9]$. Briefly, 47,325 participants (18,976 men and 28,349 women aged $\geq 20$ years old) from 152 urban street districts and 112 rural villages in 14 provinces completed the study $[8,9]$. First, 1086 persons were excluded due to the missing of demographic information or glucose level data. Second, ECG data from some subcenters (including all subcenters from Beijing, two subcenters from Hunan, two subcenters from Jiangsu and one subcenter from Xinjiang) were not well recorded; thus, data from these subcenters (data from 10,951 persons) were excluded from the analysis. Third, 100 persons missed smoking history, 93 persons missed BMI records, while 141 persons missed lipid data. Thus, 323 persons were excluded due to the missing of smoking history records, BMI records or lipid data. Ultimately, 34, 965 participants (13,983 males and 20,982 females) were included in this analysis. This study was approved by the institutional review board and the ethics committee of local institutions [8].

\section{Study-outcome definitions}

The design and methods of the China National Diabetes and Metabolic Disorders Study were reported previously $[8,9]$. Briefly speaking, interviews were conducted and standard questionnaires were completed to obtain the information about demographical characteristics, lifestyle risk factors, personal medical history, treatment of diseases and family disease history. Fasting blood samples were collected from the participants to test liver function, renal function and lipid levels. ECGs and measurements of blood pressure, waist circumference, height and weight were conducted for participants after an overnight fast by well-trained clinical staffs. Participants then received a standard oral glucose tolerance test. Diabetes mellitus was defined as fasting plasma glucose $\geq 7.00 \mathrm{mmol} / \mathrm{L}, 2$-h plasma glucose $\geq 11.10 \mathrm{mmol} / \mathrm{L}$ or using glucose-lowering medications with a history of diabetes. Prediabetes was defined as fasting plasma glucose $6.10-6.99 \mathrm{mmol} / \mathrm{L}$ or 2 -h plasma glucose $7.80-$ $11.09 \mathrm{mmol} / \mathrm{L}$ without any evidence of diagnosis of diabetes. Hypercholesterolemia was defined as total cholesterol $\geq 6.22 \mathrm{mmol} / \mathrm{L}$, LDL cholesterol $\geq 4.14 \mathrm{mmol} / \mathrm{L}$ or using cholesterol-lowering medications with a history of hypercholesterolemia. Hypertension was defined as systolic blood pressure $\geq 140 \mathrm{mmHg}$, diastolic blood pressure $\geq 90 \mathrm{mmHg}$ or using antihypertensive medications with a history of hypertension. Obesity was defined as BMI $\geq 28 \mathrm{~kg} / \mathrm{m}^{2}$, while overweight was defined as BMI 24$27.9 \mathrm{~kg} / \mathrm{m}^{2}$ according to the criteria adopted by the Chinese Society of Endocrinology. The definition of smoking history was having smoked at least 100 cigarettes in the past. Rural areas referred to rural villages. Urban areas referred to city districts. The selection of geographic regions was described in a previous article [8].

Twelve-lead ECGs were conducted with the subject in the supine position. ECGs were read and recorded by two trained physicians in each subcenter. ECG data were classified based on the Minnesota coding (MC) criteria $[1,2,5]$. Major arrhythmias included atrial fibrillation or flutter (MC 8-3), complete left bundle branch block (LBBB, MC 7-1), complete right bundle branch block (RBBB, MC 7-2), nonspecific intraventricular conduction delay (IVCD, MC 7-4), Mobitz Type II or III atrialventricular $(\mathrm{AV})$ conduction defects (MC 6-1, 6-2), supraventricular or ventricular rhythm/tachycardia (MC 8-4-1, 8-4-2, 8-2-2, 8-2-3), Wolff-Parkinson-White (WPW, MC 6-4) and artificial pacemaker (MC 6-8). Minor arrhythmias mainly included sinus bradycardia 
(MC 8-8), sinus tachycardia (MC 8-7), atrial or junctional or ventricular premature beats (MC 8-1-1, 8-1-2, 8-1-3), incomplete RBBB (MC 7-3), Mobitz Type I AV conduction defect (MC 6-3) and short PR interval (MC 6-5). Other types of ECG abnormalities were classified and analyzed as well, including ST depression and $\mathrm{T}$ abnormalities (MC 4-1, 4-2, 4-3, 4-4, 5-1, 5-2, 5-3 or 5-4), Q wave abnormalities (MC 1-1, 1-2), Q wave abnormalities plus ischemic ST-T abnormalities (MC '1-1 or 1-2' plus '4-1, 4-2, 4-3, 4-4, 5-1, 5-2, 5-3 or 5-4'), ST elevation (MC 9-2), tall $\mathrm{R}$ wave left (MC 3-1 or 3-3), tall $\mathrm{R}$ wave right (MC 3-2), left/right atrial hypertrophy (MC 9-3 or 9-6), left axis deviation (MC 2-1), right axis deviation (MC 2-2) and low voltage (MC 9-1).

\section{Statistical methods}

The prevalence calculation and significance evaluation, performed using SUDAAN software (version 10, Research Triangle Institute) in this study, were weighted to represent the population of Chinese adults ( $\geq 20$ years old) based on the Chinese population distribution data in 2006 [8]. The age- and gender- standardized prevalences of ECG abnormalities were calculated for the whole population, for males and females, and for different age groups. Multivariate logistic regression analysis was conducted using SUDAAN software (version 10, Research Triangle Institute) to investigate associations of gender, age, metabolic factors, smoking history and rural/urban areas with the odds of ECG abnormalities. Factors simultaneously adjusted to calculate the odds ratios included gender, age classes, smoking history, hypertension, blood glucose classes, BMI classes, hypercholesterolemia and rural/urban areas.

\section{Results}

This study included 34,965 participants (13,983 men and 20,982 women). The baseline characteristics of the participants are summarized in Table 1 . The mean ages of men and women were both 44.8 years old. There were no significant differences comparing the mean age $(p=$ $0.765)$ and the age classes $(p=0.886)$ between men and women. Men had significantly higher prevalences of overweight, obesity, presence of smoking history, hypertension, diabetes and presence of one or more CVD risk factors (Table 1).

The weighted prevalences of arrhythmias in men, women and all participants with different ages are summarized in Table 2. Major arrhythmias accounted for $1.70 \%$ of all participants. The weighted prevalence of major arrhythmias in men was higher than in women $(2.37 \%$ vs $1.04 \%$ in men vs women) (Table 2$)$. The weighted prevalences of major arrhythmias in the young (20-44 years old), middle (45-59 years old) and older age ( $\geq 60$ years old) groups were $1.30,2.37$ and $5.56 \%$ in men, and $0.58,1.06$ and $2.38 \%$ in women, respectively. Specifically, atrial fibrillation/flutter (MC 8-3) accounted for $0.28,0.35$ and $0.20 \%$ in the whole population, men and women respectively. Complete RBBB (MC 7-2) had the highest prevalence among all major arrhythmias, with the weighted prevalence of $0.85,1.16$ and $0.55 \%$ in the whole population, men and women respectively. Minor arrhythmias accounted for $9.92 \%$ in all participants. In the young, middle and older age groups, the weighted prevalences of minor arrhythmia were 11.05 , 10.82 and $14.26 \%$ in men, and $6.58,7.85$ and $14.17 \%$ in women, respectively. Individuals in the older age group had higher prevalences of atrial fibrillation/flutter, complete RBBB and atrial/junctional/ventricular premature beats in both men and women, compared with those in the young age group. In addition, gender had an important impact on some specific types of arrhythmia. Complete LBBB, complete RBBB, nonspecific IVCD, sinus bradycardia, incomplete RBBB and Mobitz type I AV conduction defect were more common in men than in women, while sinus tachycardia was more frequent in women than in men (Table 2).

With respect to other ECG abnormalities except arrhythmias, ST depression and $\mathrm{T}$ abnormalities and tall $\mathrm{R}$ wave left had higher prevalences than other specific ECG types (Table 3). The ST depression and T abnormalities accounted for $10.96,7.54$ and $14.32 \%$ in the whole population, men and women respectively. Tall $\mathrm{R}$ wave left accounted for 4.42, 5.83 and $3.05 \%$ in the whole population, men and women respectively. Participants in the older group had higher prevalences of ST depression and $\mathrm{T}$ abnormalities, tall $\mathrm{R}$ wave left and left axis deviation compared with those in the young group. Gender also had influence on these ECG abnormalities. Compared with women, men had significantly higher prevalences of $\mathrm{Q}$ wave abnormalities, ST elevation, tall $\mathrm{R}$ wave left, left axis deviation and right axis deviation. Women had higher prevalences of ST depression and T abnormalities and low voltage compared with men (Table 3).

To identify the factors that influence each arrhythmia ECG type, multivariate logistic regression analysis was conducted, and the results are displayed in Table 4. Male gender, older age and living in rural area were significantly associated with major arrhythmias. Older age (at least 60 years old) significantly increased the odds of having atrial fibrillation/flutter, complete LBBB, complete RBBB, nonspecific IVCD, sinus tachycardia, atrial/junctional/ventricular premature beats and Mobitz Type I AV conduction defect. Smoking was positively associated with supraventricular or ventricular rhythm/tachycardia and incomplete RBBB. Hypertension increased the odds of having sinus tachycardia and Mobitz Type I AV conduction defect. Diabetes, obesity and hypercholesterolemia were 
Table 1 Characteristics of the 34,965 participants in this study

\begin{tabular}{|c|c|c|c|}
\hline Characteristics & $\begin{array}{l}\text { Men } \\
(n=13,983)\end{array}$ & $\begin{array}{l}\text { Women } \\
(n=20,982)\end{array}$ & $P$ values $\#$ \\
\hline Age, y [mean $(95 \% \mathrm{Cl})]$ & $44.8(44.7-44.9)$ & $44.8(44.7-44.8)$ & 0.765 \\
\hline Age classes & & & 0.886 \\
\hline $20-29$ years old, $\%$ & 17.2 & 17.7 & 0.396 \\
\hline 30-39years old, \% & 23.8 & 24.0 & 0.738 \\
\hline 40-49 years old, $\%$ & 22.5 & 22.3 & 0.777 \\
\hline $50-59$ years old, $\%$ & 18.6 & 17.9 & 0.245 \\
\hline 60-69 years old, \% & 10.5 & 9.8 & 0.123 \\
\hline$\geq 70$ years old, $\%$ & 7.5 & 8.3 & 0.310 \\
\hline BMl, kg/m² [mean (95\% Cl)] & $24.1(24.0-24.2)$ & $23.5(23.4-23.5)$ & $\leq 0.001$ \\
\hline Overweight, \% & 34.9 & 29.4 & $\leq 0.001$ \\
\hline Obesity, \% & 14.0 & 10.8 & $\leq 0.001$ \\
\hline Smoking, \% & 58.2 & 3.6 & $\leq 0.001$ \\
\hline Hypertension, \% & 31.5 & 25.3 & $\leq 0.001$ \\
\hline Prediabetes, \% & 16.2 & 15.4 & 0.244 \\
\hline Diabetes, \% & 10.9 & 8.9 & $\leq 0.001$ \\
\hline FPG, mmol/L [mean (95\% Cl)] & $5.4(5.3-5.4)$ & $5.3(5.2-5.3)$ & 0.073 \\
\hline PG2h, mmol/L [mean (95\% Cl)] & $6.9(6.8-7.0)$ & $7.0(6.9-7.1)$ & 0.328 \\
\hline Hypercholesterolemia, \% & 11.1 & 10.5 & 0.244 \\
\hline Rural area, \% & 47.7 & 47.6 & 0.955 \\
\hline Urban area, \% & 52.3 & 52.4 & 0.955 \\
\hline With cardiovascular/cerebrovascular diseases, \% & 3.1 & 2.5 & 0.121 \\
\hline CVD risk groups & & & $\leq 0.001$ \\
\hline Without CVD risk factors, $\%$ & 22.2 & 60.2 & $\leq 0.001$ \\
\hline With one CVD risk factor, \% & 43.9 & 25.1 & $\leq 0.001$ \\
\hline With two CVD risk factors, $\%$ & 22.5 & 10.8 & $\leq 0.001$ \\
\hline With three or more CVD risk factors, $\%$ & 11.3 & 4.0 & $\leq 0.001$ \\
\hline
\end{tabular}

The percentages shown above were compared by Chi-square test. " The underlined numbers indicated the significant differences $(p<0.05)$. The quantitative values of age, BMI, FPG and PG2h were indicated as mean $(95 \% \mathrm{Cl})$ and compared by two-tailed t test. CVD risk factors include hypertension, diabetes, obesity, hypercholesterolemia and smoking history. Older age was not included in the CVD risk factors for analysis because age was mentioned and analyzed separately. $B M I$ body mass index, $F P G$ fasting plasma glucose level, $P G 2 \mathrm{~h}$ plasma glucose level of $2 \mathrm{~h}$ after oral glucose tolerance test, $C V D$ cardiovascular disease, $C l$ confidence interval

not positively associated with any arrhythmia ECG type. Residents living in rural area had higher odds of obtaining complete LBBB, nonspecific IVCD, sinus bradycardia and incomplete $\mathrm{RBBB}$ compared to those living in urban areas (Table 4).

Regarding the factors influencing other ECG abnormal types except arrhythmias, the results of multivariate logistic regression analysis are displayed in Table 5 . Older age (at least 60 years old) was positively associated with ST depression and T abnormalities, tall R wave left, left/ right atrial hypertrophy, left axis deviation and low voltage. Smoking was positively associated with $\mathrm{Q}$ wave abnormalities, tall $\mathrm{R}$ wave right and low voltage. Hypertension significantly increased the odds of having ST depression and $\mathrm{T}$ abnormalities, $\mathrm{Q}$ wave abnormalities, tall $\mathrm{R}$ wave left and left axis deviation (Table 5). Overweight and obesity were positively associated with ST depression and $\mathrm{T}$ abnormalities and left axis deviation (Table 5 and Supplemental Table 1). Hypercholesterolemia was positively associated with ST depression and $\mathrm{T}$ abnormalities (Table 5).

The weighted prevalences of major arrhythmias in participants with none, one, two and at least three CVD risk factors were $1.19,1.76,1.95$ and $2.17 \%$ respectively (Table 6). The presence of CVD risk factors significantly increased the odds of obtaining ST depression and $\mathrm{T}$ abnormalities, Q wave abnormalities and tall $\mathrm{R}$ wave left, after gender and age were adjusted (Table 6). A history of cardiovascular/cerebrovascular diseases significantly increased the odds of having major arrhythmias, atrial fibrillation/flutter, atrial/junctional/ventricular premature beats, ST depression and T abnormalities, Q wave 
Table 2 Prevalences of arrhythmias in men, women and all participants

\begin{tabular}{|c|c|c|c|c|c|c|c|c|c|c|}
\hline \multirow[t]{2}{*}{ ECG abnormalities } & \multirow{2}{*}{$\begin{array}{l}\text { All participants, } \\
\text { No. (percentage) }\end{array}$} & \multicolumn{4}{|c|}{ Men $(n=13,983)$} & \multicolumn{4}{|c|}{ Women $(n=20,982)$} & \multirow{2}{*}{$\begin{array}{l}\text { P value } \\
\text { (men vs } \\
\text { women) }\end{array}$} \\
\hline & & $20-44 y$ & $45-59 y$ & $\geq 60 y$ & All ages & $20-44 y$ & $45-59 y$ & $\geq 60 y$ & All ages & \\
\hline Major arrhythmias & $550(1.70 \%)$ & $1.30 \%$ & $2.37 \%$ & $5.56 \% * * *$ & $2.37 \%$ & $0.58 \%$ & $1.06 \%$ & $2.38 \% * * *$ & $1.04 \%$ & $\leq 0.001$ \\
\hline Atrial fibrillation or flutter & $77(0.28 \%)$ & $0.14 \%$ & $0.23 \%$ & $1.20 \% * *$ & $0.35 \%$ & $0.08 \%$ & $0.05 \%$ & $0.80 \% *$ & $0.20 \%$ & 0.130 \\
\hline Complete LBBB & $28(0.12 \%)$ & $0.06 \%$ & $0.20 \%$ & $0.61 \%$ & $0.20 \%$ & $0.01 \%$ & $0.03 \%$ & $0.15 \% *$ & $0.05 \%$ & $\underline{0.037}$ \\
\hline Complete RBBB & $289(0.85 \%)$ & $0.51 \%$ & $1.21 \%$ & $2.97 \% * * *$ & $1.16 \%$ & $0.35 \%$ & $0.59 \%$ & $1.10 \%^{* *}$ & $0.55 \%$ & $\underline{0.001}$ \\
\hline Nonspecific IVCD & $59(0.20 \%)$ & $0.29 \%$ & $0.43 \%$ & $0.59 \%$ & $0.38 \%$ & $0.00 \%$ & $0.06 \%$ & $0.03 \%$ & $0.02 \%$ & $\leq 0.001$ \\
\hline $\begin{array}{l}\text { Mobitz Type II or III AV } \\
\text { conduction defects }\end{array}$ & $16(0.04 \%)$ & $0.01 \%$ & $0.07 \%$ & $0.04 \%$ & $0.03 \%$ & $0.00 \%$ & $0.17 \%$ & $0.02 \%$ & $0.05 \%$ & 0.536 \\
\hline $\begin{array}{l}\text { Supraventricular or } \\
\text { ventricular } \\
\text { rhythm/tachycardia }\end{array}$ & $28(0.09 \%)$ & $0.14 \%$ & $0.14 \%$ & $0.12 \%$ & $0.14 \%$ & $0.01 \%$ & $0.10 \%$ & $0.07 \%$ & $0.05 \%$ & 0.084 \\
\hline WPW & 44 (0.09\%) & $0.14 \%$ & $0.04 \%$ & $0.02 \% * *$ & $0.09 \%$ & $0.12 \%$ & $0.04 \%$ & $0.05 \%$ & $0.09 \%$ & 0.926 \\
\hline Artificial pacemaker & $9(0.03 \%)$ & $0.01 \%$ & $0.04 \%$ & $0.00 \%$ & $0.02 \%$ & $0.00 \%$ & $0.01 \%$ & $0.16 \%$ & $0.03 \%$ & 0.117 \\
\hline Minor arrhythmias & 3046 (9.92\%) & $11.05 \%$ & $10.82 \%$ & $14.26 \% *$ & $11.58 \%$ & $6.58 \%$ & $7.85 \%$ & $14.17 \% * * *$ & $8.29 \%$ & $\leq 0.001$ \\
\hline Sinus bradycardia & 703 (2.81\%) & $3.99 \%$ & $4.29 \%$ & $3.22 \%$ & $3.94 \%$ & $1.62 \%$ & $2.03 \%$ & $1.39 \%$ & $1.70 \%$ & $\leq 0.001$ \\
\hline Sinus tachycardia & $540(1.68 \%)$ & $0.94 \%$ & $1.07 \%$ & $2.06 \% *$ & $1.18 \%$ & $1.78 \%$ & $1.38 \%$ & $4.52 \%$ & $2.14 \%$ & $\underline{0.004}$ \\
\hline $\begin{array}{l}\text { Atrial or junctional or } \\
\text { ventricular premature } \\
\text { beats }\end{array}$ & $544(1.57 \%)$ & $0.91 \%$ & $1.04 \%$ & $4.33 \% * * *$ & $1.58 \%$ & $0.87 \%$ & $1.73 \%^{* *}$ & $3.41 \% * * *$ & $1.57 \%$ & 0.945 \\
\hline Incomplete RBBB & $285(0.97 \%)$ & $1.53 \%$ & $1.47 \%$ & $0.94 \%$ & $1.40 \%$ & $0.34 \%$ & $0.85 \% *$ & $0.67 \%$ & $0.55 \%$ & $\leq 0.001$ \\
\hline $\begin{array}{l}\text { Mobitz Type I AV } \\
\text { conduction defect }\end{array}$ & $141(0.47 \%)$ & $0.43 \%$ & $0.85 \% *$ & $0.79 \%$ & $0.62 \%$ & $0.15 \%$ & $0.17 \%$ & $1.08 \%$ & $0.32 \%$ & $\underline{0.045}$ \\
\hline Short PR interval & $241(0.70 \%)$ & $0.84 \%$ & $0.26 \% *$ & $0.13 \% *$ & $0.54 \%$ & $1.02 \%$ & $0.89 \%$ & $0.34 \%^{* * *}$ & $0.86 \%$ & 0.084 \\
\hline Other minor arrhythmias & $592(1.73 \%)$ & $2.40 \%$ & $1.84 \%$ & $2.80 \%$ & $2.31 \%$ & $0.81 \%$ & $0.79 \%$ & $2.75 \%$ & $1.15 \%$ & $\leq 0.001$ \\
\hline
\end{tabular}

The percentages shown above were compared by Chi-square or Fisher's test. ${ }^{*},{ }^{*}$ and ${ }^{* * *}$ indicated the $p$ values comparing the percentages of ECG findings in the middle/older age group with those in the young age group $\left({ }^{*} \mathrm{p}<0.05,{ }^{* *} \mathrm{p}<0.01,{ }^{* * *} \mathrm{p}<0.001\right)$. ${ }^{*}$ The $p$ values revealed the differences comparing the percentages of ECG findings between men and women. The underlined $p$ values indicated the significant differences ( $p<0.05)$. LBBB left bundle branch block, $R B B B$ right bundle branch block, IVCD intravascular conducting delay, AV atrial-ventricular, WPW Wolff-Parkinson-White

Table 3 Prevalences of other ECG abnormalities (except arrhythmias) in men, women and all participants

\begin{tabular}{|c|c|c|c|c|c|c|c|c|c|c|}
\hline \multirow[t]{2}{*}{ ECG abnormalities } & \multirow{2}{*}{$\begin{array}{l}\text { All participants, } \\
\text { No. (percentage) }\end{array}$} & \multicolumn{4}{|c|}{ Men $(n=13,983)$} & \multicolumn{4}{|c|}{ Women $(n=20,982)$} & \multirow{2}{*}{$\begin{array}{l}P_{\text {Pvalue }}^{\#} \\
\text { (men vs } \\
\text { women) }\end{array}$} \\
\hline & & $20-44 y$ & $45-59 y$ & $\geq 60 y$ & $\overline{\text { All ages }}$ & $20-44 y$ & $45-59 y$ & $\geq 60 y$ & $\overline{\text { All ages }}$ & \\
\hline ST depression and T abnormalities & $4192(10.96 \%)$ & $5.26 \%$ & $9.30 \%$ *** & $11.44 \%^{* * *}$ & $7.54 \%$ & $8.36 \%$ & $18.46 \%^{* * *}$ & $25.19 \% * * *$ & $14.32 \%$ & $\leq 0.001$ \\
\hline Q wave abnormalities & $416(1.28 \%)$ & $1.35 \%$ & $1.77 \%$ & $1.86 \%$ & $1.55 \%$ & $0.78 \%$ & $1.23 \%$ & $1.31 \%$ & $1.00 \%$ & $\underline{0.003}$ \\
\hline $\begin{array}{l}\text { Q wave abnormalities plus } \\
\text { ST-T ischemic abnormalities }\end{array}$ & $75(0.16 \%)$ & $0.14 \%$ & $0.05 \%$ & $0.55 \%$ & $0.19 \%$ & $0.07 \%$ & $0.17 \%$ & $0.30 \% *$ & $0.14 \%$ & 0.414 \\
\hline ST elevation & $239(0.92 \%)$ & $2.81 \%$ & $0.88 \% \%^{* * *}$ & $0.20 \% \%^{* * *}$ & $1.78 \%$ & $0.06 \%$ & $0.16 \%$ & $0.02 \%$ & $0.08 \%$ & $\leq 0.001$ \\
\hline Tall R wave left & $1042(4.42 \%)$ & $4.94 \%$ & $7.16 \% *$ & $6.28 \%$ & $5.83 \%$ & $1.21 \%$ & $3.40 \% * * *$ & $7.89 \% * * *$ & $3.05 \%$ & $\leq 0.001$ \\
\hline Tall $\mathrm{R}$ wave right & $54(0.22 \%)$ & $0.23 \%$ & $0.13 \%$ & $0.41 \%$ & $0.23 \%$ & $0.28 \%$ & $0.06 \%$ & $0.22 \%$ & $0.20 \%$ & 0.765 \\
\hline Left/right atrial hypertrophy & $64(0.31 \%)$ & $0.21 \%$ & $0.43 \%$ & $1.05 \%$ & $0.43 \%$ & $0.06 \%$ & $0.27 \% *$ & $0.52 \% *$ & $0.21 \%$ & 0.063 \\
\hline Left axis deviation & $698(2.13 \%)$ & $1.41 \%$ & $3.31 \% * * *$ & $4.36 \% * * *$ & $2.48 \%$ & $0.98 \%$ & $2.22 \% * * *$ & $3.35 \%^{* * *}$ & $1.78 \%$ & $\underline{0.003}$ \\
\hline Right axis deviation & $254(0.67 \%)$ & $0.99 \%$ & $0.72 \%$ & $0.80 \%$ & $0.88 \%$ & $0.67 \%$ & $0.31 \% *$ & $0.15 \% * * *$ & $0.47 \%$ & 0.008 \\
\hline Low voltage & 325 (0.97\%) & $0.45 \%$ & $0.81 \%$ & $1.16 \%$ & $0.68 \%$ & $1.14 \%$ & $1.18 \%$ & $1.67 \%$ & $1.24 \%$ & 0.001 \\
\hline
\end{tabular}

The percentages shown above were compared by Chi-square or Fisher's test. ${ }^{*}{ }^{*}$ and ${ }^{* * *}$ indicated the $\mathrm{p}$ values comparing the percentages of ECG findings in the middle/older age group with those in the young age group $\left({ }^{*} p<0.05,{ }^{* *} p<0.01,{ }^{* * *} p<0.001\right)$. ${ }^{*}$ The $p$ values revealed the differences comparing the percentages of ECG findings between men and women. The underlined $p$ values indicated the significant differences $(p<0.05)$ 


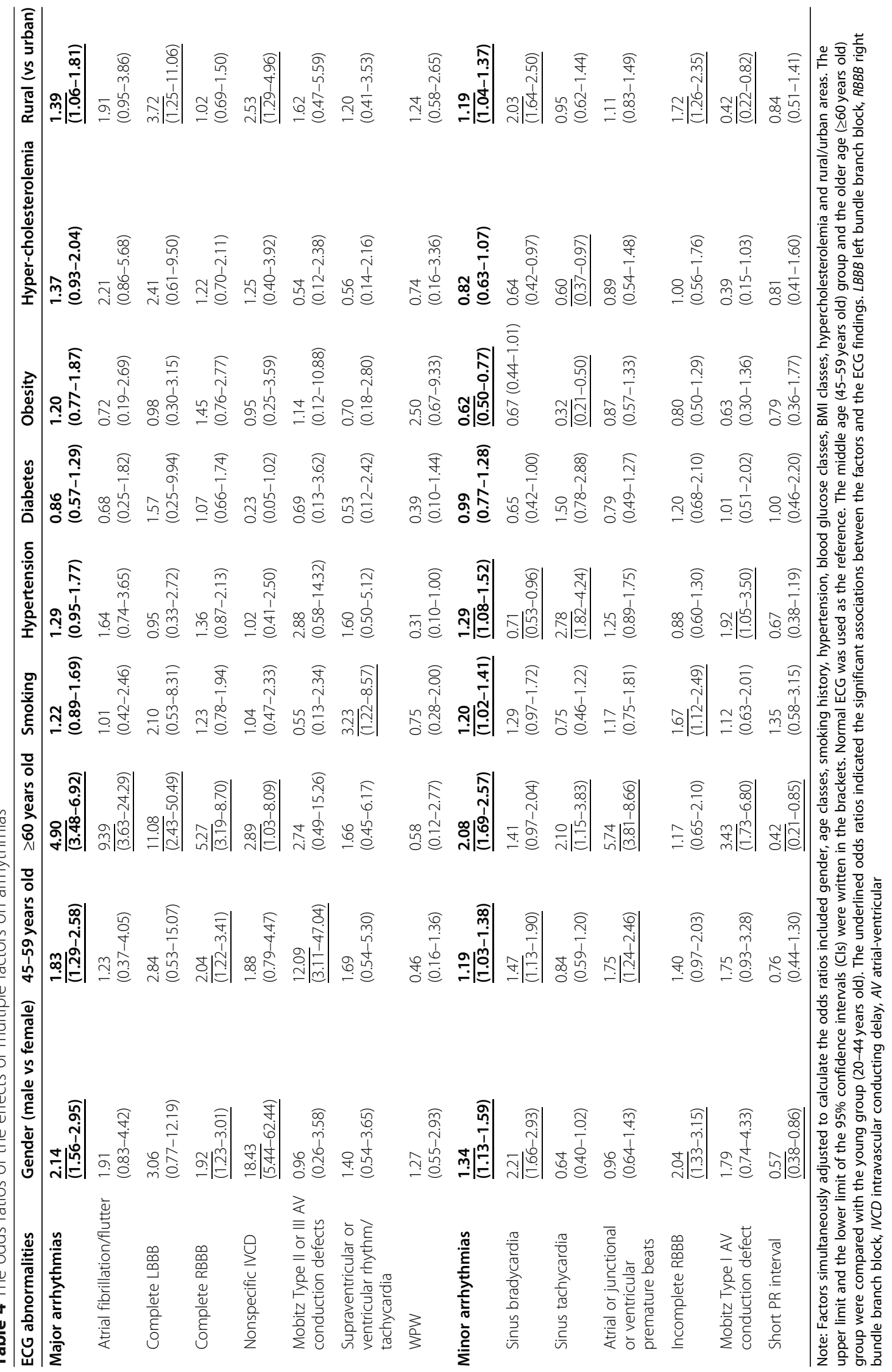




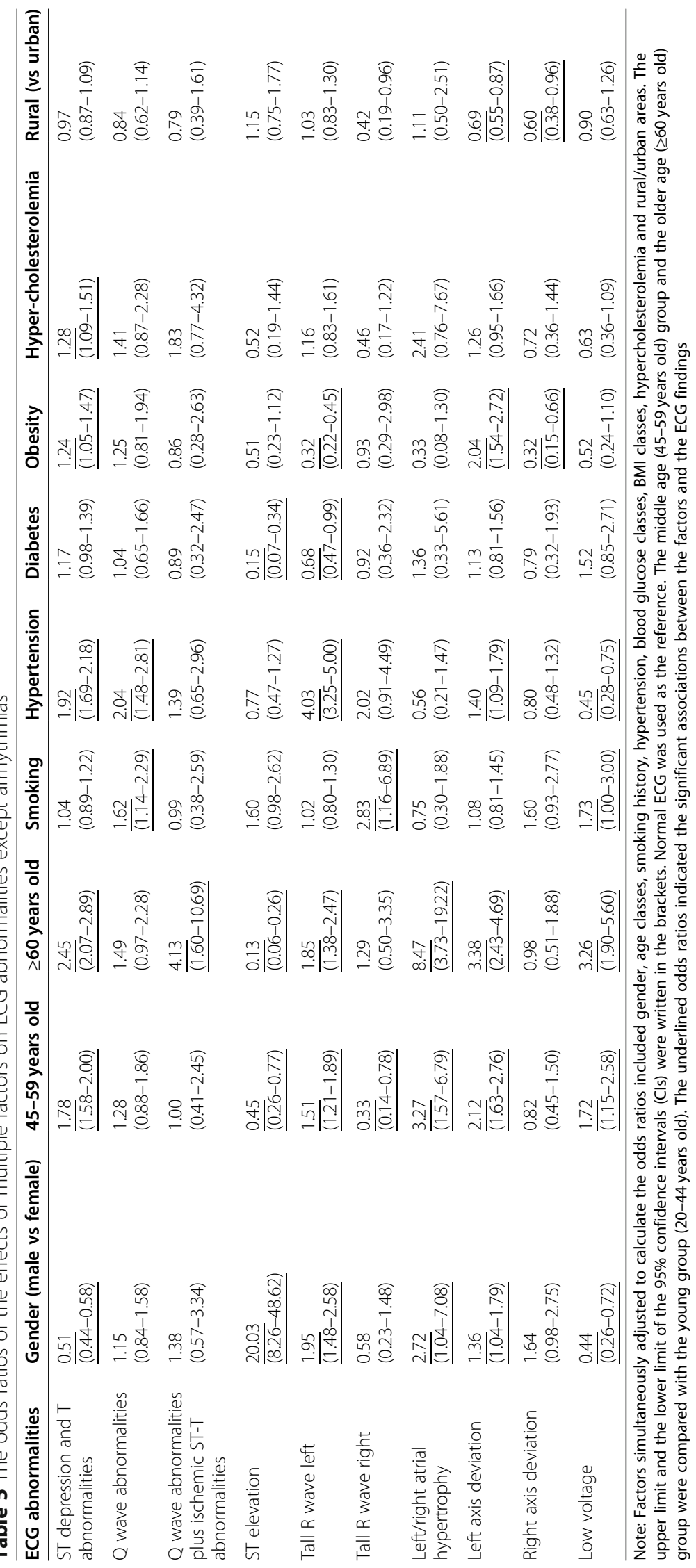


Table 6 Prevalences of ECG abnormalities with presence of CVD risk factors and history of cardiovascular/cerebrovascular diseases

\begin{tabular}{|c|c|c|c|c|c|c|}
\hline \multirow[t]{2}{*}{ ECG abnormalities } & \multicolumn{4}{|c|}{ CVD risk factors (except age and gender) } & \multicolumn{2}{|c|}{$\begin{array}{l}\text { History of cardiovascular/ } \\
\text { cerebrovascular diseases }\end{array}$} \\
\hline & None (\%) & One (\%) & Two (\%) & Three or more (\%) & Without (\%) & With (\%) ${ }^{a}$ \\
\hline Major arrhythmias & 1.19 & 1.76 & 1.95 & $2.17^{*}$ & 1.61 & $5.72^{* * *}$ \\
\hline Atrial fibrillation or flutter & 0.23 & 0.36 & 0.12 & 0.67 & 0.21 & $2.70^{* * *}$ \\
\hline Complete LBBB & 0.06 & 0.14 & 0.07 & 0.34 & 0.11 & 0.17 \\
\hline Complete RBBB & 0.55 & 0.65 & $1.32^{* *}$ & 0.78 & 0.84 & 1.99 \\
\hline Nonspecific IVCD & 0.16 & 0.25 & 0.16 & 0.27 & 0.21 & 0.48 \\
\hline Mobitz Type II or III AV conduction defects & 0.03 & 0.06 & 0.07 & 0.05 & 0.05 & 0.01 \\
\hline Supraventricular or ventricular rhythm/tachycardia & 0.05 & 0.16 & 0.14 & 0.05 & 0.09 & 0.10 \\
\hline WPW & 0.09 & 0.11 & 0.05 & 0.02 & 0.08 & 0.20 \\
\hline Minor arrhythmias & 9.38 & 11.63 & 8.84 & 10.84 & 9.95 & 9.28 \\
\hline Sinus bradycardia & 2.93 & 3.49 & 2.31 & 2.00 & 2.84 & 1.98 \\
\hline Sinus tachycardia & 1.53 & 1.82 & 1.55 & 1.72 & 1.72 & 0.70 \\
\hline Atrial or junctional or ventricular premature beats & 1.63 & 1.56 & 1.83 & 1.04 & 1.53 & $2.30^{* *}$ \\
\hline Incomplete RBBB & 0.83 & 1.36 & 0.74 & 1.31 & 0.97 & 0.67 \\
\hline Mobitz Type I AV conduction defect & 0.29 & 0.64 & 0.40 & 0.39 & 0.48 & 0.27 \\
\hline Short PR interval & 0.94 & 0.65 & 0.49 & 0.27 & 0.69 & 1.64 \\
\hline \multicolumn{7}{|l|}{ Other ECG abnormalities except arrhythmias } \\
\hline ST depression and T abnormalities & 9.82 & $10.04^{* * *}$ & $12.56^{* * *}$ & $15.36^{* * *}$ & 10.59 & $21.83^{* * *}$ \\
\hline Q wave abnormalities & 0.94 & 1.19 & $1.67^{* *}$ & $2.99 * * *$ & 1.24 & $1.88^{* *}$ \\
\hline Q wave abnormalities plus ischemic ST-T abnormalities & 0.18 & 0.11 & 0.11 & 0.31 & 0.15 & $2.16^{* *}$ \\
\hline ST elevation & 0.51 & $1.78^{*}$ & 0.43 & 0.73 & 0.92 & 0.07 \\
\hline Tall R wave left & 2.52 & $5.45^{* * *}$ & $6.11^{* * *}$ & $5.52^{* * *}$ & 4.18 & $7.62^{* *}$ \\
\hline Tall $\mathrm{R}$ wave right & 0.13 & 0.19 & $0.34^{*}$ & 0.12 & 0.21 & 0.54 \\
\hline Left/right atrial hypertrophy & 0.22 & 0.39 & 0.33 & 0.05 & 0.33 & 0.36 \\
\hline Left axis deviation & 1.60 & $2.04^{*}$ & $2.58^{* * *}$ & $3.99^{* * *}$ & 2.10 & $2.95^{*}$ \\
\hline Right axis deviation & 0.55 & 0.85 & 0.45 & 0.17 & 0.68 & 2.01 \\
\hline Low voltage & 1.46 & 0.84 & 0.49 & 0.51 & 0.96 & 0.75 \\
\hline
\end{tabular}

$\angle B B B$ left bundle branch block, RBBB right bundle branch block, IVCD intravascular conducting delay, $A V$ atrial-ventricular, $C V D$ cardiovascular disease ${ }^{*},{ }^{* *}$ and ${ }^{* * *}$ refer to $p<0.05, p<0.01$ and $p<0.001$ respectively. Gender and age were adjusted to calculate the $p$ values by multivariate logistic regression analysis. The prevalences of ECG findings in participants present with CVD risk factors was compared with those absent of CVD risk factors

${ }^{a}$ The prevalences of ECG findings in participants with history of cardiovascular/cerebrovascular diseases was compared with those without history of cardiovascular/cerebrovascular diseases

abnormalities, tall $\mathrm{R}$ wave left and left axis deviation, with gender and age adjusted (Table 6). The weighted prevalence of major arrhythmias in participants with a history of cardiovascular/cerebrovascular diseases was as high as $5.72 \%$, while the prevalence in those without the history was only $1.61 \%$ (Table 6 ).

\section{Discussion}

Previous prospective studies have found that baseline major and minor ECG abnormalities have different levels of impact on the risk of CVD events and all-cause mortality, suggesting that it is crucial to identify and classify baseline ECG abnormalities [4, 5, 10-14]. The prevalences of ECG findings varied in different races. Middle-aged black men had significantly higher prevalence of major
ECG abnormalities than middle-aged white men [15, 16]. Non-Hispanic population had significantly higher prevalences of atrial fibrillation, left ventricular hypertrophy and ST depression than Hispanic population [17]. Taiwan Chinese women aged at least 40 years old had higher prevalence of major ECG abnormalities than American White women of about the same age [18]. Currently, no population-based estimation of the prevalence of ECG abnormalities has been reported in China. The ECG data contained in the present study were obtained from a large population in a cross-sectional study. The present data provide overall estimates of the prevalence of ECG findings in Chinese adults (aged $\geq 20$ years old) and the relationships between ECG abnormalities and gender, age and CVD risk factors. 
Ethnicity is an important factor affecting the prevalences of ECG findings. We compared our study with previous population-based studies that had similar age range as ours but had different racial background. The prevalences of some arrhythmias in our study were close to the results in a study of American Hispanics/Latinos aged 18-74 years old and another study of Belgians aged 25-74 years old $[1,2]$. In these two foreign studies, atrial fibrillation or flutter accounted for $0.30-0.55 \%$ in men and $0.04-0.33 \%$ in women $[1,2]$. In our study, the weighted prevalences of atrial fibrillation or flutter were 0.35 and $0.20 \%$ in men and women respectively, which were between the ranges of these two previous studies. Complete RBBB was the most prevalent arrhythmia type in the American Hispanics/Latinos study and the Belgian study, as well as in our study $[1,2]$. In our study, complete RBBB accounted for 1.16 and $0.55 \%$ in men and women respectively, which were also between the ranges reported in these two previous studies $[1,2]$. However, we had higher prevalences of WPW, Mobitz Type II or III AV conduction defects and supraventricular or ventricular rhythm/tachycardia, but lower prevalences of nonspecific IVCD and artificial pacemaker, compared with the American Hispanics/Latinos study [2]. With regard to ST-T abnormalities, because some subcenters in our study recorded the ST depression and $\mathrm{T}$ wave abnormalities together and did not differentiate the major and minor ST-T abnormalities, we eventually calculated the prevalence of ST depression (MC 4-1, 4$2,4-3,4-4)$ and $\mathrm{T}$ abnormalities (MC 5-1, 5-2, 5-3 or 5-4) together in the population. ST depression and T abnormalities accounted for 7.54 and $14.32 \%$ in men and women respectively in our study, while the prevalences of ST depression and $\mathrm{T}$ abnormalities were approximately 8 and $10 \%$ in men and women respectively in the American Hispanics/Latinos study [2].

The weighted prevalences of several ECG abnormalities increased with age in both men and women in our study, confirming the age-related increase in the prevalence of these ECG abnormalities reported in previous studies $[1-3,19,20]$. Older age (at least 60 years old) increased the likelihood of having atrial fibrillation/flutter by about 8 times, while metabolic and geographic factors had no significant association with atrial fibrillation/flutter in comparison with the reference group (20-44 years old) (Table 4). Older age not only increased the prevalence of atrial fibrillation/flutter in cross-sectional studies, but also increased the incidence of atrial fibrillation/ flutter in retrospective and prospective studies, suggesting that older age had tremendous association with atrial fibrillation/flutter [1, 21, 22]. The likelihoods of having complete LBBB and complete RBBB in the 60 years old or older group were both more than 4 times higher than those in the reference group (20-44 years old) in our study (Table 4). A Korean cross-sectional study also found that the prevalences of complete LBBB and complete RBBB both increased with age [23]. In addition, older age also significantly increased the prevalences of ST depression and T abnormalities, tall $\mathrm{R}$ wave left and left/right atrial hypertrophy. These results suggest that it is essential to conduct ECG regularly for people at lease 60 years old to screen ECG abnormalities especially arrhythmias.

Among the ECG abnormalities, atrial fibrillation/flutter was broadly studied before and recently. Atrial fibrillation/flutter, well known as a critical risk factor for stroke, was also indicated as an independent risk factor for ventricular fibrillation in a population-based casecontrol study [24]. In a cross-sectional study of participants aged at least 35 years old in China, the prevalences of atrial fibrillation were 0.78 and $0.76 \%$ in men and women, respectively [7]. The inclusion of a history of atrial fibrillation in addition to ECG records and the older age of the participants could have contributed to the higher prevalence of atrial fibrillation observed in this previous study than in our study [7]. The factors associated with atrial fibrillation/flutter were mainly older age and the history of cardiovascular/cerebrovascular diseases (Tables 4 and 6). However, in contrast to previously reported studies, we found that smoking history, hypertension, diabetes, obesity and hypercholesterolemia were not significantly related with atrial fibrillation $[7,25]$. The prevalence of having atrial fibrillation/flutter in participants with a history of cardiovascular/cerebrovascular diseases was as high as $2.7 \%$, which were much higher than the prevalence in those without the history. The prevalence of atrial fibrillation varied from 0.6 to $4.1 \%$ in patients with cardiovascular diseases in previous studies, while the prevalence of cardiovascular diseases was as high as $38.2 \%$ in patients with atrial fibrillation [26-28]. Atrial fibrillation had close association with cerebrovascular diseases especially stroke $[29,30]$. The famous Framingham Study indicated that there was a nearly fivefold excess of stroke in the subjects with atrial fibrillation compared with those free of atrial fibrillation after 34 years of follow-up [30]. Therefore, it is important to screen atrial fibrillation/flutter in patients with cardiovascular/cerebrovascular diseases.

The odds of having ischemic ST-T abnormalities significantly increased with hypertension, obesity and hypercholesterolemia, confirming the association between metabolic factors and ischemic ECG abnormalities $[1,2]$. Metabolic factors, including hypertension, obesity and hypercholesterolemia, significantly increased the risk of having ischemic heart diseases in prospective studies [31, 32]. It is important to identify and control these metabolic factors in order to prevent ischemic heart diseases. High R wave left is a main ECG manifestation of left ventricular hypertrophy. Our study and 
previous studies all presented that hypertension was a key associated factor for left ventricular hypertrophy or high $\mathrm{R}$ wave left [33, 34]. Another previous study followed up hypertensive patients for a mean time of approximately 10 years and found that left ventricular hypertrophy significantly increased the risk of CVD events [35]. Thus, it is crucial to identify left ventricular hypertrophy in hypertensive patients, while ECG provides a convenient way to identify it. Meanwhile, blood pressure control in hypertensive patients can prevent the development of left ventricular hypertrophy [36].

Our study had some limitations. First, the original design of the ECG recording didn't include PR, QRS, QT and QTc interval durations and heart rates. Some subcenters recorded the ST depression and $\mathrm{T}$ wave abnormalities together; thus, the major ST-T abnormalities could not be differentiated from the minor ST-T abnormalities. Second, there was some observer bias due to different observers in different subcenters. However, in each subcenter, two well-trained physicians read the ECG, checked with each other, and then recorded the ECG results. If they could not reach a consensus about the ECG result, they would consult the ECG specialists in the Project Committee. The consensus of two well-trained physicians on each ECG might reduce some inter-observer and intra-observer bias. Third, we didn't follow up these participants to investigate the progression of ECG findings and metabolic characteristics. In addition, there were about $24 \%$ participants excluded from the ECG analysis mainly due to the lack of ECG data. However, we analyzed the characteristics of the participants included and those excluded in this article (Supplemental Table 2). The proportions of the two genders and the proportions of the six age classes, which were the two most important demographic characteristics, showed no significant differences between the included participants and the excluded participants.

\section{Conclusions}

Our study provides estimates of the prevalences of ECG findings in Chinese adults. Gender, age, CVD risk factors and history of cardiovascular/cerebrovascular diseases were significantly associated with ECG abnormalities.

\section{Supplementary information}

Supplementary information accompanies this paper at https://doi.org/10. 1186/s12872-020-01698-5.

Additional file 1: Table S1. The odds ratios of the effects of prediabetes and overweight on ECG abnormalities. Table S2. Comparison of the characteristics of the included and excluded populations

\section{Abbreviations}

ECG: Electrocardiogram; MC: Minnesota coding; CVD: Cardiovascular diseases; LBBB: Left bundle branch block; RBBB: Right bundle branch block; IVCD: Intraventricular conduction delay; AV: Atrial-ventricular; WPW: WolffParkinson-white; CHD: Coronary heart disease

\section{Acknowledgements}

We acknowledge the China National Diabetes and Metabolic Disorders Study Group. We are grateful for all the colleagues who contributed in the China National Diabetes and Metabolic Disorders Study. We thank all the participants in this study.

\section{Authors' contributions}

Liping Yu, Xiaojun Ye and Bo Zhang analyzed and interpreted the ECG data. Zhaojun Yang helped with the analysis of the data. Liping Yu wrote the draft of the manuscript. Xiaojun Ye and Bo Zhang revised the manuscript carefully. Zhaojun Yang and Wenying Yang provided suggestions for the revision of the manuscript. Wenying Yang designed the China National Diabetes and Metabolic Disorders Study. All authors have read and approved the final version of the manuscript.

\section{Funding}

The analysis and interpretation of the data in this study were supported by the National Natural Science Foundation of China (grant number: 2017YFC1309705, Beijing, China). The design of the study and data collection of the survey were supported by the Chinese Medical Association Foundation and Chinese Diabetes Society.

\section{Availability of data and materials}

The datasets used and/or analyzed in the current study are available from the corresponding author upon reasonable request.

\section{Ethics approval and consent to participate}

The China National Diabetes and Metabolic Disorders study was approved by the Ethics Review Board of China-Japan Friendship Hospital and the ethics committee of local institutions. The secondary objectives of the China National Diabetes and Metabolic Disorders study included the analysis of ECG abnormalities which was approved during the original ethical review.

\section{Consent for publication}

Not applicable.

\section{Competing interests}

The authors have no competing interests.

\section{Author details}

'Department of Endocrinology, China-Japan Friendship Hospital, Beijing, China. ${ }^{2}$ Department of Cardiology, China-Japan Friendship Hospital, Beijing, China.

Received: 4 May 2020 Accepted: 2 September 2020

Published online: 11 September 2020

References

1. De Bacquer D, De Backer G, Kornitzer M. Prevalences of ECG findings in large population based samples of men and women. Heart. 2000;84(6):625-33.

2. Denes P, Garside DB, Lloyd-Jones D, Gouskova N, Soliman EZ, Ostfeld R, et al. Major and minor electrocardiographic abnormalities and their association with underlying cardiovascular disease and risk factors in Hispanics/Latinos (from the Hispanic community health study/study of Latinos). Am J Cardiol. 2013;112(10):1667-75

3. Pinto-Filho MM, Brant LCC, Foppa M, Garcia-Silva KB, Mendes de Oliveira RA, de Jesus Mendes da Fonseca M, et al. Major Electrocardiographic abnormalities according to the Minnesota coding system among Brazilian adults (from the ELSA-Brasil cohort study). Am J Cardiol. 2017;119(12):2081-7.

4. Liao YL, Liu KA, Dyer A, Schoenberger JA, Shekelle RB, Colette P, et al. Major and minor electrocardiographic abnormalities and risk of death from coronary heart disease, cardiovascular diseases and all causes in men and women. J Am Coll Cardiol. 1988;12(6):1494-500.

5. Denes P, Larson JC, Lloyd-Jones DM, Prineas RJ, Greenland P. Major and minor ECG abnormalities in asymptomatic women and risk of cardiovascular events and mortality. Jama. 2007;297(9):978-85.

6. Lin L, Chen G, Zou X, Zhao J, Zhu F, Tu M, et al. Diabetes, pre-diabetes and associated risks on Minnesota code-indicated major electrocardiogram abnormality among Chinese: a cross-sectional diabetic study in Fujian province, Southeast China. Obes Rev. 2009;10(4):420-30. 
7. Li Y, Wu YF, Chen KP, Li X, Zhang X, Xie GQ, et al. Prevalence of atrial fibrillation in China and its risk factors. Biomed Environ Sci. 2013;26(9):709-16.

8. Yang W, Lu J, Weng J, Jia W, Ji L, Xiao J, et al. Prevalence of diabetes among men and women in China. N Engl J Med. 2010;362(12):1090-101.

9. Yang W, Xiao J, Yang Z, Ji L, Jia W, Weng J, et al. Serum lipids and lipoproteins in Chinese men and women. Circulation. 2012:125(18):2212-21.

10. Auer R, Bauer DC, Marques-Vidal P, Butler J, Min LJ, Cornuz J, et al. Association of major and minor ECG abnormalities with coronary heart disease events. Jama. 2012;307(14):1497-505.

11. Cedres BL, Liu K, Stamler J, Dyer AR, Stamler R, Berkson DM, et al. Independent contribution of electrocardiographic abnormalities to risk of death from coronary heart disease, cardiovascular diseases and all causes. Findings of three Chicago epidemiologic studies. Circulation. 1982;65(1): 146-53.

12. De Bacquer D, De Backer G, Kornitzer M, Blackburn H. Prognostic value of ECG findings for total, cardiovascular disease, and coronary heart disease death in men and women. Heart. 1998:80(6):570-7.

13. Machado DB, Crow RS, Boland LL, Hannan PJ, Taylor HA Jr, Folsom AR. Electrocardiographic findings and incident coronary heart disease among participants in the atherosclerosis risk in communities (ARIC) study. Am J Cardiol. 2006;97(8):1176-81.

14. Sutherland SE, Gazes PC, Keil JE, Gilbert GE, Knapp RG. Electrocardiographic abnormalities and 30-year mortality among white and black men of the Charleston heart study. Circulation. 1993;88(6):2685-92.

15. Walsh JA, Prineas R, Daviglus ML, Ning H, Liu K, Lewis $C E$, et al. Prevalence of electrocardiographic abnormalities in a middle-aged, biracial population: Coronary Artery Risk Development in Young Adults study. J Electrocardiol. 2010;43(5):385.e1-9.

16. Prineas RJ, Le A, Soliman EZ, Zhang ZM, Howard VJ, Ostchega Y, et al. United States national prevalence of electrocardiographic abnormalities in black and white middle-age (45- to 64-year) and older ( $>/=65$-year) adults (from the reasons for geographic and racial differences in stroke study). Am J Cardiol. 2012;109(8):1223-8.

17. Perez MV, Yaw TS, Myers J, Froelicher VF. Prognostic value of the computerized ECG in Hispanics. Clin Cardiol. 2007;30(4):189-94.

18. Wu CC, Yeh WT, Crow RS, Bai CH, Pan WH. Comparison of electrocardiographic findings and associated risk factors between Taiwan Chinese and US white adults. Int J Cardiol. 2008;128(2):224-31.

19. Furberg CD, Manolio TA, Psaty BM, Bild DE, Borhani NO, Newman A, et al. Major electrocardiographic abnormalities in persons aged 65 years and older (the cardiovascular health study). Cardiovascular health study collaborative research group. Am J Cardiol. 1992;69(16):1329-35.

20. Rose G, Baxter PJ, Reid DD, McCartney P. Prevalence and prognosis of electrocardiographic findings in middle-aged men. Br Heart J. 1978;40(6): 636-43.

21. Mandalenakis Z, Lennartsson ST, Fu M, Lappas G, Li S, Rosengren A, et al. The incidence of atrial fibrillation and the added value of thumb ECG for detecting new cases. Scand Cardiovasc J. 2018;52(5):256-61.

22. Lane DA, Skjøth F, Lip GYH, Larsen TB, Kotecha D. Temporal Trends in Incidence, Prevalence, and Mortality of Atrial Fibrillation in Primary Care. J Am Heart Assoc. 2017;6(5):e005155.

23. Jeong JH, Kim JH, Park YH, Han DC, Hwang KW, Lee DW, et al. Incidence of and risk factors for bundle branch block in adults older than 40 years. Korean J Intern Med. 2004;19(3):171-8.

24. Bardai A, Blom MT, van Hoeijen DA, van Deutekom HW, Brouwer HJ, Tan $\mathrm{HL}$. Atrial fibrillation is an independent risk factor for ventricular fibrillation: a large-scale population-based case-control study. Circ Arrhythm Electrophysiol. 2014;7(6):1033-9.

25. Chan NY, Choy CC. Screening for atrial fibrillation in 13122 Hong Kong citizens with smartphone electrocardiogram. Heart. 2017;103(1):24-31.

26. Otterstad JE, Kirwan BA, Lubsen J, De Brouwer S, Fox KA, Corell P, et al. Incidence and outcome of atrial fibrillation in stable symptomatic coronary disease. Scand Cardiovasc J. 2006;40(3):152-9.

27. Cameron A, Schwartz MJ, Kronmal RA, Kosinski AS. Prevalence and significance of atrial fibrillation in coronary artery disease (CASS registry). Am J Cardiol. 1988;61(10):714-7.

28. Wyse DG, Waldo AL, DiMarco JP, Domanski MJ, Rosenberg Y, Schron EB, et al. A comparison of rate control and rhythm control in patients with atrial fibrillation. N Engl J Med. 2002;347(23):1825-33.

29. Proietti M, Mairesse GH, Goethals P. Scavee C, Vijgen J, Blankoff I, et al. Cerebrovascular disease, associated risk factors and antithrombotic therapy in a population screening cohort: insights from the Belgian heart rhythm week programme. Eur J Prev Cardiol. 2017;24(3):328-34.

30. Wolf PA, Abbott RD, Kannel WB. Atrial fibrillation as an independent risk factor for stroke: the Framingham study. Stroke. 1991;22(8):983-8.

31. D'Agostino RB Sr, Vasan RS, Pencina MJ, Wolf PA, Cobain M, Massaro JM, et al. General cardiovascular risk profile for use in primary care: the Framingham heart study. Circulation. 2008;117(6):743-53.

32. Poirier P, Giles TD, Bray GA, Hong Y, Stern JS, Pi-Sunyer FX, et al. Obesity and cardiovascular disease: pathophysiology, evaluation, and effect of weight loss: an update of the 1997 American Heart Association scientific statement on obesity and heart disease from the obesity Committee of the Council on nutrition, physical activity, and metabolism. Circulation. 2006; 113(6):898-918.

33. Li T, Chen S, Guo X, Yang J, Sun Y. Impact of hypertension with or without diabetes on left ventricular remodeling in rural Chinese population: a crosssectional study. BMC Cardiovasc Disord. 2017;17(1):206.

34. Cuspidi C, Facchetti R, Quarti-Trevano F, Sala C, Tadic M, Grassi G, et al. Incident left ventricular hypertrophy in masked hypertension. Hypertension. 2019;74(1):56-62.

35. Lehtonen AO, Puukka P, Varis J, Porthan K, Tikkanen JT, Nieminen MS, et al. Prevalence and prognosis of ECG abnormalities in normotensive and hypertensive individuals. J Hypertens. 2016;34(5):959-66.

36. Soliman EZ, Ambrosius WT, Cushman WC, Zhang ZM, Bates JT, Neyra JA, et al. Effect of intensive blood pressure lowering on left ventricular hypertrophy in patients with hypertension: SPRINT (systolic blood pressure intervention trial). Circulation. 2017;136(5):440-50.

\section{Publisher's Note}

Springer Nature remains neutral with regard to jurisdictional claims in published maps and institutional affiliations.

Ready to submit your research? Choose BMC and benefit from:

- fast, convenient online submission

- thorough peer review by experienced researchers in your field

- rapid publication on acceptance

- support for research data, including large and complex data types

- gold Open Access which fosters wider collaboration and increased citations

- maximum visibility for your research: over $100 \mathrm{M}$ website views per year

At $\mathrm{BMC}$, research is always in progress.

Learn more biomedcentral.com/submissions 